\title{
Instituições e políticas regionais: uma proposta para a nova Sudene
}

\author{
DINILSON PEDROZA JÚNIOR \\ THIAGO ALEXANDRO N. ANDRADE \\ CRISTINE VIEIRA DO BONFIM*
}

Institutions and regional policies: a proposal for the new Sudene. Sudene is the Brazilian Federal Agency for Northeast development. The Agency was recreated last year and this article discusses the possibility of its success. The main point argued here is that financial incentives per se are not the best way for a sustained economical and social progress. It is necessary a change in the institutions which maintain the status quo of the underdevelopment. The article shows the Sudene history and the motives of its failure.

Keywords: regional development; public policies; Sudene.

JEL Classification: R58; D02.

\section{INTRODUÇÃO}

O problema regional é, antes de tudo, um problema de desigualdade. Desigualdade no padrão de desenvolvimento de regiões que compõem um mesmo espaço político-administrativo. É natural presumir que as regiões de um país, qualquer que seja ele, se desenvolvam de maneira desigual ${ }^{1}$. É igualmente natural o desconforto diante de situações de desigualdade muito acentuadas.

\footnotetext{
* Dinilson Pedroza Jr. é professor do Departamento de Economia da Universidade Católica de Pernambuco, técnico em Informações Estatísticas do Instituto Brasileiro de Geografia e Estatística. Endereço para correspondência: Departamento de Contas Públicas. Praça Ministro João Gonçalves de Souza, s/n. Edificio Sudene, Quarto andar, Ala Sul. Recife (PE). E-mail: dinilson.junior@ibge.gov.br. Thiago Alexandro Andrade é aluno do curso de Ciências Econômicas da Universidade Católica de Pernambuco, pesquisador pelo Programa de Iniciação Científica (PIBIC/UNICAP). E-mail: thiagoeconomista@ hotmail.com. Cristine Vieira do Bonfim é pesquisadora da Fundação Joaquim Nabuco (FUNDAJ) do Ministério da Educação. E-mail: cristine.bonfim@fundaj.gov.br. Submetido: 13/mar./2008; Aprovado: 11/fev./2010.

${ }^{1}$ Assim define Kaldor (1989, p. 311) o problema regional: "diferentes regiões crescendo a taxas desiguais; com algumas se desenvolvendo relativamente mais rápido e outras sendo deixadas para trás”.
} 
Como ciência social, a Economia deve propor soluções para esse tipo de problema. Amartya Sen, Prêmio Nobel de Economia de 2001, afirma inclusive que "toda teoria normativa do ordenamento social que tenha, afinal, resistido ao teste do tempo parece exigir a igualdade de algo - algo que é considerado como particularmente importante nessa teoria" (Sen, 2001, pp. 43-44).

A justificativa para uma busca pela igualdade regional é encontrada também em Galvão (1998):

Há, hoje, disponível um considerável corpo da literatura que reconhece o fato de que disparidades regionais que persistem por longos períodos de tempo produzem efeitos negativos sobre a operação eficiente da economia nacional, além de danosas consequências de ordem política, social e institucional. (Galvão, 1998, p. 762)

Ainda segundo o autor, a ausência de uma política regional, ou sua má condução, pode gerar ressentimento, tanto nas regiões mais atrasadas quanto nas mais desenvolvidas. Tal ressentimento pode minar as bases da solidariedade entre populações das diferentes localidades, fazendo surgir posicionamentos separatistas.

Uma sociedade regionalmente mais igualitária poderia, além disso, "reduzir a demanda por capital social, em nível nacional, em vista do comprovado fato de que a criação de capital social em áreas menos congestionadas tem custos mais baixos do que sua ampliação nas áreas de forte densidade demográfica e de elevada concentração de atividades econômicas” (p. 763).

Tanto é assim, que a maior parte dos países, não importa seu grau de desenvolvimento, praticam ou praticaram algum tipo de política de desenvolvimento regional. Os Estados Unidos da América, país arquétipo da tradição liberal e não intervencionista, também fez uso de políticas para desenvolver regiões atrasadas.

A Autoridade do Vale do Tennessee (TVA), hoje uma das maiores empresas públicas norte-americanas, foi o órgão criado pelo governo americano, em 1934, para recuperar áreas afetadas pelas inundações do rio Tennessee.

David Lilienthal (1944), artífice, primeiro e mais importante presidente do órgão, escreveu que, não fosse sua ação democrática e consensual, o TVA não teria alcançado o êxito que alcançou. A modificação da paisagem da região só aconteceu como resultado da participação popular nas decisões mais importantes sobre a alocação de recursos do órgão:

A cada ano e quase a cada mês, era possível ver a participação do povo, como prática fundamental, crescer de maneira vigorosa e, embora tenha sofrido algum retrocesso, tal prática tem se tornado parte do modo de pensar e da mecânica do desenvolvimento do Vale do Tennessee. (Lilienthal, 1944, p. 87)

O TVA não é, contudo, o único exemplo de ação regional nos Estados Unidos. A Região Sul, tradicionalmente mais atrasada, passou, ao longo do século passado, por um vigoroso processo de mudança em suas instituições. Essas mudanças foram impostas pelo governo americano justamente para viabilizar seu desenvolvimento. 
Gavin Wrigth (1986), historiador econômico norte-americano, pondera que a intervenção federal foi decisiva para a transformação econômica e social no Sul dos Estados Unidos. A ação foi focalizada nas instituições responsáveis pelo atraso, procurando modificá-las ou mesmo eliminá-las. Esta não foi uma tarefa fácil. Apenas na década de 1960 é que estados sulistas foram forçados a se desfazer de instituições segregacionistas.

Na Europa, mesmo antes da constituição da União Europeia, fez-se uso de política de combate à desigualdade regional. O caso da Itália foi particularmente inspirador ao Brasil. Como nos EUA, é o Sul a região considerada subdesenvolvida do país. Esse atraso, secular, motivou a criação na década de 1950 da Cassa per il Mezzogiorno, órgão que tinha por finalidade desenvolver o Sul predominantemente agrário ${ }^{2}$.

No âmbito da União Europeia, a política regional mais recente tem buscado uma abordagem mais participativa e definida em base local (Moseley, 1999). A União Europeia tem se revelado, aliás, um enorme laboratório para políticas de integração econômica e social, tamanha a diversidade de suas regiões e países.

Os estados-membros possuem uma população total de 370 milhões de habitantes e, coletivamente, incluem uma grande variedade de culturas, línguas e histórias de desenvolvimento econômico. Muito embora, em termos globais, a União Europeia seja próspera, ela exibe sérios contrastes interiores em matéria de riqueza e oportunidades. Isto é verdadeiro não apenas no nível nacional, mas particularmente, entre regiões individuais. (Moseley, 1999, p. 69)

No que diz respeito à prática europeia, é possível se falar em mudança de paradigma. Em contraposição a um modelo de intervenção que privilegia a ação através do fortalecimento dos polos de crescimento, os atuais programas de desenvolvimento regional são elaborados com base na noção de desenvolvimento endógeno. O desenvolvimento endógeno é aquele que procura potencializar o uso dos recursos locais objetivando a ampliação da capacidade de desenvolver-se dessas mesmas comunidades (Jaccoud, 2001, p. 11).

Portanto, não há nada de especificamente brasileiro na proposição e execução de políticas regionais. Radicalismos liberais à parte, as políticas regionais não devem ser condenadas por princípio, a julgar pela prática internacional. No Brasil existem dispositivos constitucionais que obrigam o Estado brasileiro a planejar e executar políticas regionais ${ }^{3}$. Independentemente deles, os números apresentados a seguir permitem qualificar a região como um problema que merece uma atenção especial.

\footnotetext{
${ }^{2}$ O TVA, assim com a italiana Casa per il Mezzogiorno, são vistos por Williamson (1968, p. 160) como exemplos de como o governo pode agir em prol de uma distribuição espacial da riqueza mais equitativa, aplacando, assim, "a análise excessivamente pessimista de Myrdal” sobre o processo de desenvolvimento das regiões.

${ }^{3}$ Ver Constituição Federal, Seção IV, “Das Regiões”, Artigo 43.
} 


\section{OS NÚMEROS DA DESIGUALDADE}

A desigualdade regional mais evidente no Brasil é apresentada em números nesta seção. Quando da criação da Sudene, a mais importante iniciativa para combater tal desigualdade, em 1959, a participação do PIB do Nordeste no PIB nacional era de 14,41\% ${ }^{4}$. Em 2005 este número chegou a 13,06\%, uma redução, portanto. Em 2004 esta participação foi de 12,72\%.

Em 1959 o PIB per-capita do Nordeste era o equivalente a 28,41\% do PIB per-capita do Sudeste e 42,39\% do PIB per-capita do Brasil's. Em 2005 estes números eram, respectivamente, 35,54\% (NE/SE) e 47,16\% (NE/BR). Como não há números disponíveis sobre taxas de crescimento por Unidade da Federação desde 1959, resta argumentar que em termos per-capita, o que realmente importa, diga-se de passagem, o Nordeste apresentou melhora relativa. Contudo, não se pode dizer que uma renda per-capita que é apenas metade da nacional significa um êxito inquestionável das políticas regionais.

Dado revelador é o referente a uma das informações mais precisas sobre as condições de vida de uma população: taxa de mortalidade infantil ${ }^{6}$. Em 1997 esta taxa era de 50,36, no Nordeste. Um número 2,18 vezes superior ao do Sudeste e 1,58 vezes maior que a taxa brasileira.

Em 2005 a taxa nordestina cai para 38,2. Esta expressiva redução aconteceu durante o período de maior desgaste da Sudene. Durante esses anos, o órgão limitava-se, basicamente, a administrar os recursos do FINOR.

Este é, por conseguinte, um resultado que deve ser atribuído às políticas setoriais dos governos federal e estaduais. Na América Latina, a taxa de mortalidade infantil do Nordeste só era menor que a da Bolívia $(54,0)$, Guiana $(47,0)$ e a do Haiti $(74,0)^{7}$.

Outra variável que expressa o padrão de vida e, portanto, o grau de desenvolvimento é a associada à condição sanitária. O percentual de domicílios com o serviço de rede coletora de esgotamento sanitário no Nordeste em 2006 era de 40,4. Para o Brasil este número era de $66,2 \%$. No Sudeste, $89,1 \%$ dos domicílios eram atendidos pelo serviço, uma dos mais necessários à vida digna nos centros urbanos.

Agora a causa (e consequência) de todos os problemas, o analfabetismo. A taxa de analfabetismo do Brasil em 2005 foi de $11,3 \%{ }^{8}$. A taxa do Nordeste chegou

\footnotetext{
${ }^{4}$ Para estes e demais dados antigos, Estatística do Século XX, publicação do IBGE de 2005. Os dados mais recentes das contas regionais foram publicados em dezembro de 2007, com informações até 2005 .

${ }^{5}$ Ajustes levaram em consideração o fato de que em 1959 a hoje conhecida Região Sudeste não existia. A então Região Nordeste não incluía os estados da Bahia e Sergipe. São Paulo fazia parte da Região Sul.

${ }^{6}$ Definida como o número de óbitos infantis (menos de 1 ano de vida) por mil nascidos vivos. Os números aqui apresentados constam no sítio do Datasus, do Ministério da Saúde, na publicação Síntese de Indicadores Socias, 2006, do IBGE.

${ }^{7}$ Os números da América Latina são de 2004 e foram obtidos no sítio da Organização Mundial de Saúde (OMS).

${ }^{8}$ Taxa de analfabetismo correspondente às pessoas de 15 anos ou mais. Na América Latina, o valor do Nordeste só é inferior aos da Guatemala, Nicarágua e Haiti.
} 
a 21,9\%: quase duas vezes superior à média nacional e mais de três vezes a taxa do Sudeste $(6,5 \%)$.

Números mais alarmantes são os da taxa de analfabetismo funcional. Um analfabeto funcional apenas sabe ler. Por causa de seu escasso tempo na educação formal, não consegue interpretar um texto, qualquer que seja ele, com precisão. A taxa do Nordeste foi de $36,3 \%$, em 2005, para um número nacional de $23,5 \%$. Quando esta medida diferencia população urbana da rural, chega-se a números absurdos. O Nordeste rural tem mais da metade de sua população qualificada como analfabeta funcional $(56,7)$. No Piauí e em Alagoas, mais de $60 \%$ da população rural é analfabeta funcional ${ }^{9}$.

As consequências mais diretas dessa falta de qualificação generalizada são percebidas na remuneração média do trabalho: em 2005 o rendimento médio mensal dos trabalhadores nordestino foi de $\mathrm{R} \$ 490,40$, para um valor do Brasil de $\mathrm{R} \$ 800,80$.

O propósito desses números foi o de evidenciar que a Região Nordeste merece ainda uma atenção especial. Assim como ocorreu em 1959, quando a Sudene foi criada. Como, então, a instituição atuou em seus mais de 40 anos de existência?

\section{POLÍTICAS REGIONAIS NO BRASIL: O CASO DA SUDENE}

Criada em 1959 para promover o desenvolvimento na região mais atrasada do país, a Sudene não foi a primeira iniciativa com esse objetivo. Isso porque a miséria a qual estava e está submetida grande parte da população da região sempre chocou, em particular, nas ocasiões de secas frequentes.

De acordo com Andrade (1999, p. 34), a população sertaneja está preparada para enfrentar secas de até oito meses. Para tanto, ela utiliza os velhos e seculares instrumentos de que dispõe para reservar água em situações emergenciais: açudes, represas, cisternas, entre outros. Se a seca se prolongar por vários anos, as reservas se esgotam, forçando parte da população a migrar.

É este fluxo migratório de "miseráveis" que tem comovido, ao longo dos séculos, as autoridades públicas brasileiras. "De acordo com registros históricos, houve 85 anos de secas no Nordeste, nos séculos XVIII, XIX e XX [...] Dessa forma, em um sentido bem concreto, respaldado por 300 anos de história, as secas (a cada dois anos e meio) são a regra, não a exceção" (Maia Gomes, 2001, p. 75) ${ }^{10}$.

Não obstante condições de vida inóspitas, o sertão nordestino foi largamente povoado por pessoas que exploravam basicamente a pecuária extensiva, processo este descrito em Formação Econômica do Brasil, de Celso Furtado (2007). Com a implantação das unidades produtoras de açúcar veio a necessidade de animais de

\footnotetext{
${ }^{9}$ Os maiores números são os seguintes, sempre para a população rural: PI $(62,0 \%)$, Alagoas $(60,4 \%)$ e Maranhão (59,1\%), dados na Síntese dos Indicadores Sociais de 2006.

${ }^{10}$ A seca acontecida entre os anos de 1877 e 1879 foi de grande importância para a caracterização do Nordeste como área problema no país. O quadro foi particularmente impressionante no Ceará, o que motivou a frase do imperador Dom Pedro II: "Não restará uma única joia na Coroa, mas nenhum nordestino morrerá de fome” (apud Andrade, 1999, p. 34).
} 
tiro. Contudo, era inviável que tal criação se desse dentro das próprias unidades produtoras, o que levou a atividade pecuária a distanciar-se da faixa litorânea. Segundo Furtado:

Ao expandir-se a economia açucareira, a necessidade de animais de tiro tendeu a crescer mais que proporcionalmente, pois a devastação das florestas litorâneas obrigava a buscar a lenha a distâncias cada vez maiores. Por outro lado, logo se evidenciou a impraticabilidade de criar o gado na faixa litorânea, isto é, dentro das próprias unidades produtoras de açúcar. Os conflitos provocados pela penetração de animais em plantações devem ter sido grandes, pois o próprio governo português proibiu, finalmente, a criação de gado na faixa litorânea. (Furtado, 2007, p. 96)

Como resultado dos primeiros diagnósticos a abordagem hidráulica caracterizou boa parte das ações federais durante a primeira metade do século XX. Como observa Cohn (1976, p. 57): "Dos fins do século passado até a década de 1950, a atuação do Governo Federal no Nordeste se caracterizou por ser de socorro ao flagelo ocasionado pelas secas" 11 .

Não obstante esse viés hidráulico, Oliveira (1977, p. 50) afirma que a intervenção do Estado no combate às secas foi "a primeira manifestação do planejamento da atividade governamental para resolver os problemas da economia regional”.

Outra seca, a de 1951, motivou outra reação por parte do Governo Federal. Ficou evidente, àquela altura, que o problema do subdesenvolvimento nordestino não teria como única causa a seca ${ }^{12}$. Em 1952 é criado o Banco do Nordeste do Brasil (BNB). Coube ao primeiro presidente do banco, Rômulo Almeida, a iniciativa, em 1954, de elaborar um plano de desenvolvimento para o Nordeste. Refletindo, 30 anos depois, sobre aqueles momentos, Rômulo Almeida afirmou:

A mensagem do Presidente Vargas ao Congresso Nacional, apresentando projeto do Banco do Nordeste - BNB - representou uma primeira mudança de posição: o Nordeste não é um caso de assistência, é um problema econômico e político a ser enfrentado com racionalidade e grandeza. (Almeida, 1985, p. 137)

O BNB e o DNOCS não eram, contudo, as únicas instituições federais a tentar resolver o problema do atraso na região.

Já na década de 1940, por inspiração do Tennessee Valley Authorithy, foram criadas duas agências com área de atuação no Vale do Rio São Francisco: a Comis-

\footnotetext{
${ }^{11}$ Em 1909 é criada a Inspetoria Federal de Obras Contra as Secas (IFOCS), que em 1945 seria transformada em Departamento Nacional de Obras Contra a Seca (DNOCS). As iniciativas empreendidas pelo DNOCS foram de importância para a elaboração de uma abordagem científica ao problema das secas. Tratou-se, como o qualificou Oliveira (1977), de um esforço racionalizador na busca de uma solução definitiva para o problema.

${ }^{12}$ Robock (1964) descreve em detalhes a mudança de paradigma no Governo Federal.
} 
são (depois Companhia) do Vale do São Francisco e a Companhia Hidrelétrica do São Francisco (CHESF).

O que motivou a criação da Comissão foi "o crescente entusiasmo mundial pelo desenvolvimento integrado de bacias fluviais, despertado pela experiência do TVA” (Robock, 1964, p. 95).

No plano estadual, vale mencionar a iniciativa da Comissão de Desenvolvimento de Pernambuco (CODEPE), que convidou o padre dominicano francês, Louis Joseph Lebret (1955), conhecido especialista em desenvolvimento econômico, para realizar estudo indicando localização para instalações industriais em Pernambuco. O padre Lebret era, na França, líder de um grupo de estudos econômicos, o "Economia e Humanismo", que entendia ser a planificação regional um instrumento para o engrandecimento do homem e não apenas para enriquecer grupos econômicos restritos e determinadas camadas sociais.

Em 1953 existiam, portanto, pelo menos três órgãos federais, mais os estaduais, cujo objetivo era a promoção do desenvolvimento do Nordeste. Como relata Robock (1964), havia a clara necessidade de se coordenar as ações das instituições na busca de um objetivo comum.

Ficou evidente a necessidade de um órgão coordenador das diversas ações. Em 1956, por sugestão de técnicos do BNB, o presidente Juscelino Kubitschek comprou a ideia de uma ação coordenada na região e instituiu o Grupo de Trabalho para o Desenvolvimento do Nordeste (GTDN), o qual estaria ligado diretamente à sua pessoa (Decreto $\mathrm{n}^{\circ}$ 40.554, de 14 de dezembro de 1956).

Some-se a isto a iniciativa, por parte da Igreja Católica, em discutir soluções para o problema da seca. Com esse objetivo foi realizado em maio de 1956 o Primeiro Encontro dos Bispos do Nordeste, do qual participou a própria Presidência da República.

Um segundo encontro dos bispos, realizado em 1959, procurou comprometer, a exemplo do que já havia acontecido no primeiro, o Governo Federal na adoção de medidas práticas para minorar a situação de penúria que acometia grande parte da população nordestina.

Os bispos desejavam "ver o planejamento econômico, elaborado para o Nordeste completado por aspectos humanos e por implicações sociais" (Declaração dos Bispos do Nordeste, 1959).

O GTDN, quando esteve à frente Celso Furtado, pretendeu oferecer uma visão radical dos problemas enfrentados pela sociedade nordestina. A intenção era a de apresentar "um conjunto de recomendações concretas que, levadas à prática, poderão modificar os dados desse (problema nordestino) e encaminhar uma solução definitiva do mesmo" (GTDN, 1959, p. 7). Nada menos.

O documento caracteriza o problema regional através de números que evidenciam a disparidade de riquezas entre as regiões brasileiras; por exemplo, enquanto a renda per-capita do chamado Centro-Sul era de US\$ 303, a do Nordeste era de apenas $1 / 3$ deste valor. Valor que correspondia à metade da renda per-capita brasileira.

Mas a que se devia atribuir esse subdesenvolvimento da Região Nordeste em relação ao Brasil? 
O GTDN (1959) aponta os seguintes fatores como determinantes do atraso regional:

- Relações Econômicas desfavoráveis do Nordeste para com o Centro-Sul do país;

- Gastos do setor público que privilegiam a região mais rica do país;

- Existência de um arcabouço institucional que perpetua, na região, o atraso econômico e social.

O documento do GTDN (1959) é bastante comedido ao apontar a estrutura fundiária como elemento de atraso da região. Não há, no texto, qualquer referência à reforma agrária.

Em entrevista dada há dez anos, Celso Furtado (1998, p. 34), embora mantivesse sua posição inicial de que é preciso "levar gente para outras áreas, para o Maranhão, colonizar onde há terras abundantes”, menciona como alternativa a recolonização de terras da Zona da Mata mediante a desocupação de áreas economicamente improdutivas.

Segundo o GTDN, o vetor de transformação da paisagem econômica nordestina seria a industrialização. Nesse aspecto, é possível dizer, o documento filia-se à tradição cepalina que defendia a mudança na estrutura produtiva de um país como condição necessária ao seu desenvolvimento ${ }^{13}$.

- "O GTDN conclui [...] que a industrialização seria a única solução”, viável para o desenvolvimento da Região (Goodman e Albuquerque, 1964, p. 160).

- O documento causou boa impressão ao presidente Kubitschek que, de pronto, transformou o GTDN em Conselho de Desenvolvimento Econômico do Nordeste (CODENO), instituição que seria transformada, logo depois, na Sudene.

A Lei que criou a autarquia foi aprovada e promulgada em 15 de dezembro de 1959, começando a funcionar em março do ano seguinte, incorporando para tanto a equipe e o programa do CODENO (Robock, 1964).

Todavia, a criação da Sudene não foi vista com bons olhos pelos que se sentiam ameaçados por uma mudança brusca no status quo ou arranjo institucional que prevalecia na região. Oliveira (1977) lembra que a oposição à criação do órgão foi bem maior, no Congresso Nacional, por parte dos parlamentares nordestinos ${ }^{14}$. $\mathrm{O}$ apoio foi dado principalmente pelos congressistas do Centro-Sul, aliados a poucos, mas expressivos, parlamentares nordestinos mais ligados à burguesia mais progressista.

A oposição não foi, contudo, forte o suficiente para evitar o surgimento do órgão. Até porque a situação social na região era tida por muitos analistas como explosiva. Explosiva a ponto de o governo norte-americano, receoso de uma difu-

\footnotetext{
${ }^{13}$ Sobre esta filiação, consultar Silva Filho (1997) e Lafer (1997).

${ }^{14}$ Furtado (1997, p. 132) é ainda mais enfático quanto a este tópico: "Em realidade, a Lei foi aprovada contra a maioria das bancadas nordestinas, graças ao apoio majoritário dos deputados do Centro".
} 
são do "efeito Cuba" pela América Latina, defender o que deveria ser uma solução técnica para a miséria nordestina:

Com efeito, o apoio do governo norte-americano à criação de um organismo que se propõe a solucionar o problema do Nordeste em termos novos, diante do potencial explosivo que se identifica na região, é evidenciado [também] por editoriais do jornal O Estado de São Paulo (COHN, 1976, p. 82).

Querelas políticas à parte, não se pode negar o aspecto inovador representado pela Sudene. O mesmo Presidente da República que decretou sua extinção em 2001 havia escrito anteriormente que:

Mais consistente como técnica de planejamento global e como forma de ruptura do sistema tradicional de decisões foi a Sudene, na medida em que sua Superintendência e seu Conselho, para poder implementar as políticas adotadas a partir de critérios técnicos [...] tiveram de interferir diretamente nas áreas de decisão privativas dos governadores e na política dos partidos de clientela, bem como tiveram que constituir em pouco tempo, um corpo e burocratas com objetivos técnicos. (Cardoso, 1997, p. 175)

Barros (1997), que também destaca o aspecto inovador da proposta do GTDN $^{15}$, observa que a intenção do órgão em agir em diversas frentes para elevar o nível de renda e alcançar para o Nordeste uma situação econômica menos dependente do Centro-Sul do país é acertada, pois, do contrário, os prognósticos a respeito do plano tornam-se inviáveis.

Já Oliveira (1977) nota ainda que a Sudene deteve, quando de sua criação, a capacidade, inteiramente inédita no quadro político-administrativo do país, de criar empresas mistas, combinando capitais da União, dos Estados e do setor privado. A ideia foi a de tornar o Estado também produtor no Nordeste:

Praticamente em qualquer ramo das atividades econômicas poderia a Sudene implantar essas empresas estatais, como de fato as implantou, desde empresas destinadas ao abastecimento d'água nas cidades até uma unidade de produção industrial tão inequívoca quanto a USIBA — Usinas Siderúrgicas da Bahia. O Estado nunca tinha sido produtor no Nordeste, salvo em poucos casos; esse novo Estado no Nordeste já se apresentava sem a marca de sua ambigüidade no Centro-Sul. (Oliveira, 1977, p. 116)

\footnotetext{
15 “A partir daí, tenta-se formular uma nova estratégia: a solução do problema não estaria na oferta de água, mas sim num conjunto mais amplo de medidas que assegurassem o desenvolvimento econômico da região como um todo, tornando-a assim, menos dependente das variações pluviométricas" (Barros, 1997, p. 119).
} 
A Sudene operou em grande parte de sua existência, com uma estrutura dual: uma Secretaria Executiva, que em tese seria responsável pela elaboração de propostas técnicas, e um Conselho Deliberativo, cuja finalidade era a de consolidar propostas e demandas dos governos estaduais. Cabia ainda à Secretaria Executiva a administração do que se tornou, na prática, o carro-chefe do órgão, o Fundo de Investimentos do Nordeste (FINOR).

Com o passar dos anos, as reuniões do Conselho, que durante os primeiros anos da Sudene eram bastante concorridas, simplesmente deixaram de interessar aos governadores ${ }^{16}$. Até mesmo os ministros menosprezaram o Conselho, enviando como seus representantes, técnicos de segundo e terceiro escalões.

Da forma como foi pensada, a Sudene representava o Estado dentro do Estado. Esta noção é reforçada pelo gigantismo do prédio construído para abrigá-la. Evidentemente, muitos a viam, principalmente em seus últimos anos, como uma desnecessária duplicação de tarefas dentro do próprio Governo Federal.

Por outro lado, os governadores, com acesso mais direto ao poder federal, achavam mais proveitoso se dirigirem diretamente àquele poder, evitando, assim, a intermediação de um espaço político que, ademais, era bem mais público e demandava esforço - leia-se custo - de negociação com os seus pares nordestinos.

Durante as décadas de 1970 e 1980, a Sudene perdeu identidade funcional: se o Ministério da Educação pretendia desenvolver determinado programa na região ele o fazia sem passar pelo crivo dos governadores em assembleia e, muito menos, pela avaliação técnica da Secretaria Executiva do órgão.

A perda de identidade fez com que a Sudene fosse vista apenas como o órgão que administrava o FINOR. Bresser-Pereira (1998) diz ter havido uma mudança fundamental nos objetivos e métodos da Sudene em relação àqueles propostos por Celso Furtado. O órgão, que deveria ser um instrumento de repasse de fundos públicos para a economia nordestina, com a participação dos estados, "na verdade, transformou-se [através de seu mecanismo de incentivos] no veículo de transferência de capital industrial do Sul para o Nordeste" (Bresser-Pereira, 1998, p. 96)"

Criticada durante toda a sua existência ${ }^{17}$, o que ficou sendo a razão de ser do órgão, a administração do FINOR, passou a sofrer críticas ainda mais contundentes em fins dos anos 1990. As críticas e denúncias quanto ao mau uso dos recursos do Fundo motivaram a extinção do órgão, por Medida Provisória assinada em maio de 2001 pelo então Presidente da República Fernando Henrique Cardoso ${ }^{18}$.

As denúncias foram alimentadas, em grande parte, por uma Comissão Parlamentar de Inquérito (CPI) instalada em 18/4/2000 para averiguar irregularidades na liberação e aplicação de recursos do FINOR. A CPI realizou audiências e colheu

\footnotetext{
${ }^{16}$ Segundo o pesquisador sobre o tema, Ricardo Emmanuel Ismael de Carvalho, em entrevista dada ao Jornal do Commercio em 11/8/2002, entre 1987 e 1998, período no qual foram realizados mais de 100 encontros, a Sudene conseguiu reunir todos os governadores em quatro ocasiões. E só contou com a presença simultânea dos governadores da Bahia, de Pernambuco e do Ceará em 15 oportunidades.

${ }^{17}$ Exemplos dessa crítica encontram-se em Tamer (1968), Oliveira (1977), Almeida (1985), Carvalho (1988) e, mais recentemente, Bresser-Pereira (1998), Villa (2000) e Gomes (2001).

${ }^{18}$ Medida Provisória n 2.146, de 4 de maio de 2001.
} 
depoimentos, bem como visitou empresas beneficiadas. Entre as irregularidades encontradas pela CPI estão desde fiscalizações "realizadas numa situação caótica" (Relatório Final CPI-FINOR, p. 46) até a emissão de notas "frias" por parte de algumas empresas.

Pensado para reduzir a concentração da atividade econômica entre as grandes regiões do país, o mecanismo de incentivos administrado pela Sudene foi criticado exatamente por permitir ou mesmo instigar a concentração intrarregional.

De acordo com o Relatório Final da CPI-FINOR, datado de maio de 2001, a distribuição espacial de projetos concluídos evidenciava a concentração de projetos concluídos nos três estados mais ricos da região, Pernambuco (22\%), Bahia $(19 \%)$ e Ceará $(17 \%)$. Estes estados juntos receberam o equivalente a $63 \%$ das liberações dos recursos do Fundo para projetos concluídos.

Recriada através de Lei Complementar em janeiro de $2007^{19}$, resta saber até que ponto a "nova" Sudene dispõe de um modelo mais avançado de intervenção no principal problema regional brasileiro.

Em seu Artigo 14 é dito que compete ao órgão avaliar o cumprimento do Plano Regional de Desenvolvimento Regional. Neste plano devem constar metas puramente econômicas, tais como geração de emprego e renda e metas sociais, como redução da mortalidade infantil e melhoria das condições de habitação. Contudo é mantida a ênfase nos Fundos para a promoção do crescimento econômico, o Fundo Constitucional de Financiamento do Nordeste e Fundo de Desenvolvimento do Nordeste. O primeiro seria mais voltado para o financiamento de infraestrutura da região. O segundo é muito semelhante ao antigo FINOR: dinheiro para a empresa que quiser instalar uma unidade na região.

Os termos secos da Lei não permitem, dessa forma, vislumbrar uma mudança na maneira de pensar o desenvolvimento regional. Essa será uma preocupação a ser discutida, se o for, no momento em que o tal plano, o outro instrumento da nova Sudene, estiver sendo elaborado.

Como já previsto no GTDN, o desenvolvimento regional não será alcançado sem um modelo de intervenção que procure afetar as instituições responsáveis pelo atraso da região. Essas instituições precisam ser mapeadas, debatidas e, se possível, transformadas. Afinal, não é sem razão que a Teoria Econômica reconhece a importância do arranjo institucional para progresso.

\section{INSTITUIÇÕES E DESENVOLVIMENTO ECONÔMICO}

Agências governamentais e organismos internacionais têm reconhecido que a teoria econômica convencional não tem proporcionado sugestões de políticas que, uma vez implementadas, alcancem plenamente os objetivos para os quais foram concebidas $^{20}$.

\footnotetext{
${ }^{19}$ Lei Complementar n 125, de 3 de janeiro de 2007.

${ }^{20}$ Ver, por exemplo, o Relatório de Desenvolvimento Humano de 1997, produzido pelo Banco Mundial.
} 
Já em 1973, Albert Hirschman observou que as propostas de políticas sugeridas por consultores internacionais não ajudavam muito na superação do subdesenvolvimento dos países da América Latina.

Agências governamentais e organismos internacionais de cooperação têm percebido, cada vez mais, que, para se alcançar um crescimento econômico mais sustentável e equitativo, não é suficiente aplicar reformas no mercado, desenhar políticas econômicas sofisticadas, dispor de bons programas de investimentos ou construir infraestrutura básica. Além de boas políticas é necessário contar com instituições mais eficientes (Espino, 1999, p. 11).

A diferença no desempenho econômico dos países pode ser explicada, em grande parte, por diferenças em suas instituições. Logo, uma teoria das instituições pode ser um guia útil para definir qual tipo de arranjo institucional é o mais apropriado à tarefa de promover o desenvolvimento regional.

Essa forte associação entre desenvolvimento econômico e instituições é explorada por Arthur W. Lewis, Prêmio Nobel de Economia de 1979. Lewis (1965) se propôs, em seu clássico A Teoria do Crescimento Econômico, de 1954, a investigar as causas do desenvolvimento.

Foi o primeiro grande estudo com o objetivo explícito de ser um tratado geral sobre o desenvolvimento econômico desde os Princípios de Economia Política, de John Stuart Mill, de 1848.

Um segundo fator contribuiu para a grande repercussão da obra: a ênfase atribuída às instituições como condicionantes do crescimento econômico. $\mathrm{O}$ crescimento depende, segundo Lewis (1965, p. 10), "por um lado, dos recursos naturais disponíveis e, no outro, do comportamento humano". Por comportamento humano deve-se entender a forma segundo a qual as instituições são criadas, transformadas ou superadas.

As instituições conformam o ambiente que serve de estrutura para o desenvolvimento das sociedades. As perguntas que Lewis procura responder são:

[...] que tipos de instituições são favoráveis ao crescimento e quais são inimigas do esforço, da inovação ou do investimento. Devemos, a seguir, adentrar no reino das crenças e perguntar o que leva uma nação a criar instituições que são favoráveis, ao invés de inimigas, ao crescimento? (Lewis, 1965 , p. 11)

Lewis (1965) deixa claro, como o também premiado pelo Nobel de Douglass C. North o fará mais tarde, que algumas instituições podem contribuir para o desenvolvimento enquanto outras, não. O estudo da relação entre instituições e desempenho econômico é dificultado pela imprecisão em identificar com exatidão as mudanças institucionais. Imprecisão acentuada quando o pesquisador é contemporâneo daquelas mudanças.

Apesar das dificuldades em se alcançar preceitos universais sobre que instituições são favoráveis ao crescimento, Lewis (1965) deduz que:

Nossa investigação sobre compatibilidade das instituições e do crescimento levou à conclusão de que as instituições promovem o crescimen- 
to na medida em que associam esforço e recompensa, na medida em que permitem a especialização e o comércio e na medida em que liberam a busca e a construção de oportunidades econômicas. (Lewis, 1965, p. 142)

As mudanças institucionais que permitem o crescimento econômico são, por este, influenciadas, o que leva a um processo cumulativo. Mas é exatamente essa interação entre oportunidades econômicas, crenças e instituições que torna difícil discernir uma única causa para a mudança institucional.

Karl Polanyi, considerado pai da Economia Institucional, escreveu, em 1944, que a ênfase em aspectos puramente econômicos embotou uma percepção mais acurada sobre os processos por trás do desenvolvimento. Segundo ele, "o liberalismo econômico interpretou mal a história da Revolução Industrial porque insistiu em julgar os acontecimentos sociais a partir de um ponto de vista econômico" (Polanyi, 2000, p. 52).

Imaginar que a parte significativa dos problemas relativos ao subdesenvolvimento é econômica pode levar a uma subestimação do esforço necessário ao desenvolvimento. Frequentemente, como narra Polanyi (2000), a intervenção de natureza política é necessária ao salto rumo ao desenvolvimento.

O que é tido como puramente econômico em absoluto o é: "a economia de mercado é uma estrutura institucional” (Polanyi, 2000, p. 56). Para Polanyi (2000) as leis de mercado só são relevantes no cenário institucional de uma economia de mercado.

A importância desse cenário institucional é também ressaltada por Max Weber em sua mais importante obra, Economia e Sociedade.

O funcionamento de uma ordem econômica do tipo moderno não é possível sem uma ordem jurídica de caráter muito especial, a qual, na prática, só poder ser uma ordem estatal [...] a economia moderna baseia-se em oportunidades adquiridas por contratos. (Weber, 1991, p. 226)

A religião também estaria relacionada à ordem econômica. É por demais conhecida a associação que Weber (1991) fez entre a ética protestante e a lógica capitalista.

A criação de uma ética capitalista somente foi obra - ainda que não intencionada - do ascetismo intramundano do protestantismo, o qual abriu aos elementos mais poderosos e eticamente mais rigorosos o caminho à vida dos negócios. (Weber, 1991, pp. 391-392)

Este tema da importância da ética protestante para a formação do capitalismo foi revisitado por David Landes (1998), historiador econômico de Harvard. Landes (1998) produziu um livro cujo objetivo era o de, à maneira de Smith, investigar as causas da pobreza e da riqueza dos países. Para ele, fator determinante para o sucesso eram os arranjos institucionais que predominaram nas diversas formações sociais.

Landes (1998, p. 248) observa que termos como valores culturais "não são 
populares entre os economistas, que preferem lidar com fatores quantificáveis. Entretanto, sendo a vida o que é temos que falar dessas coisas".

Por mais bem-dotado de recursos naturais seja um país ou região, essa riqueza de nada servirá para sua evolução social se o país ou região não foi dotado, também, de instituições favoráveis ao desenvolvimento.

Quando a sociedade está dividida em um punhado de latifundiários privilegiados e uma grande massa de trabalhadores pobres, dependentes talvez escravizados - com efeito, entre uma escola para a indolência (a do hedonismo) em contrate com o atoleiro de desânimo — onde está o incentivo para mudar ou progredir? (Landes, 1998, p. 331)

A relevância do elemento institucional como determinante do desenvolvimento econômico é analisada ainda por Douglass C. North. Prêmio Nobel de Economia de 1993.

North (1994) é enfático ao afirmar que "o desempenho econômico é função das instituições e de sua evolução". As instituições, segundo ele, constituem as regras do jogo de uma sociedade, ou, mais formalmente, "representam os limites estabelecidos pelo homem para disciplinar as interações humanas. Consequentemente $[. .$.$] estruturam incentivos de natureza política, social e econômica" (North,$ 1994, p. 9).

As instituições devem ser vistas, segundo North em seu Instituições, Mudança Institucional e Performance Econômica, de 1990, como a afirmação da continuidade entre o passado, o presente e o futuro. North (1990), como vários economistas modernos ${ }^{21}$, atribui à História uma importância crucial na explicação dos fenômenos econômicos e sociais, quando diz que "as escolhas de amanhã são moldadas pelo passado" (p. vii). Instituições são definidas como "arcabouço dentro do qual as interações humanas acontecem” (North, 1990, p. 4).

North (1990) entende as instituições como estruturas que limitam a ação humana. As decisões são tomadas pelos agentes para um dado arranjo institucional. Esta forma de conceber as instituições torna a sua análise complementar às abordagens neoclássicas: é como se fosse possível considerar a restrição imposta pelo arranjo institucional como argumento de uma função de produção. Isso não quer dizer, entretanto, que instituições não se modifiquem. Mudanças institucionais acontecem frequentemente como resultado de negociações políticas ${ }^{22}$.

Assim como os agentes tomam decisões sobre qual a melhor organização a ser estruturada para um dado ambiente institucional, a escolha sobre a melhor instituição deve se dar, também, em bases racionais. Ocorre que nem sempre o que é racional é facilmente discernível.

\footnotetext{
${ }^{21}$ Entre eles merecem destaque David (1985), Arthur (1998), Krugman (1996).

22 Em 1957, Downs (1999), em seu Uma Teoria Econômica da Democracia, procurou racionalizar a ação política micromotivada dos agentes. A sua intenção era criar uma teoria que explicasse o chamado "paradoxo da ação coletiva": decisões e ações micromotivadas podem aparecer, numa perspectiva macro, como irracionais.
} 
Não raras vezes, o que é tido por um observador superficial como uma decisão irracional esconde, na verdade, interesses ocultos. Nesse caso, o agente que tomou a decisão que aparentemente contraria a lógica estaria jogando jogos ocultos (Tsebelis, 1998). "Somente o estudo de toda a rede de jogos em que o ator está envolvido revelará as motivações desse ator e explicará seu comportamento" (Tsebelis, 1998, p. 20).

Tsebelis (1998) entende que a ocorrência de escolhas não ideais são, na verdade, casos em que há discordância entre o observador e o agente que escolhe: "o que parece subótimo a partir da perspectiva de um único jogo é na verdade ótimo quando é considerada toda a rede de jogos” (Tsebelis, 1998, p. 22).

Quando da criação da Sudene, em 1959, os setores mais progressistas do país entenderam que aquela era uma forma de intervenção inovadora na região. Uma intervenção racional que objetivasse a solução definitiva para os problemas do Nordeste por meio de ações radicais. A ideia era evitar a adoção de medidas meramente paliativas como tinham sido as chamadas soluções hidráulicas para o problema do subdesenvolvimento nordestino. Só que essa intervenção, por meio da criação da instituição Sudene, se daria em um ambiente socioeconômico retrógrado, no qual imperava o clientelismo como prática política. Jogos, ocultos ou não, estavam sendo jogados por quem defendia a manutenção de um conjunto de instituições desfavoráveis ao desenvolvimento.

Situação inversa à experimentada pelos Estados Unidos. North (1990) observa que os elementos favoráveis ao crescimento econômico predominaram, a ponto de tornarem a sociedade norte-americana bem mais progressista e igualitária que a de países em desenvolvimento: "O arcabouço institucional político e econômico desenvolvido nas colônias americanas e, posteriormente, nos EUA, levou ao surgimento de uma economia dinâmica e produtiva" (North, 1994, p. 25).

As organizações, criadas como instrumentos operativos de arranjos institucionais, precisam estar imbuídas do que North (1990) chamou de eficiência adaptativa. A flexibilidade, por outro lado, não pode ser tal que permita comportamentos erráticos ou oportunistas. A regularidade nas regras institucionais é condição sine qua non para o desenvolvimento de uma sociedade.

A organização por excelência de uma economia de mercado é a empresa, alvo das políticas de incentivos ao desenvolvimento tradicionais. No seminal "A Natureza da Firma", de 1937, Ronald Coase, prêmio Nobel de economia de 1991, investigou os condicionantes institucionais das empresas. Para Coase, o sistema econômico está, apenas, parcialmente coordenado pelo sistema de preços. Mesmo em uma sociedade empresarial, na qual a intervenção de governo seja reduzida, o resultado econômico não depende apenas do que acontece nos mercados. No interior de uma empresa a alocação de recursos é configurada pela hierarquia organizacional.

Segundo Coase, a empresa e o mercado são formas alternativas de organização das transações econômicas. Em 1937 Coase preocupou-se em explicar o surgimento das firmas, entendendo que é a redução nos custos de transação a principal 
justificativa para a formação das empresas ${ }^{23}$ : por que depender de relações comerciais quando seja viável requisitar insumos a um departamento da mesma empresa?

A finalidade de uma política de incentivos regionais é atrair uma firma para uma região pouco desenvolvida. Tal política, para ser efetiva, deve reconhecer a natureza institucional das empresas. Os incentivos alteram o balanço entre vender em um mercado e produzir nele. Este é um balanço volúvel, sujeito às mais diversas mudanças no ambiente empresarial. A promoção do desenvolvimento regional calcada apenas nesse instrumento seguramente não produz resultados de longo prazo.

Transações econômicas dentro de uma empresa tornam desnecessária a confecção de contratos. O contrato é uma expressão legal das transações entre empresas. Ocorre que, para Oliver Williamson (1996), Prêmio Nobel de 2009, os contratos estão fundados em dois pressupostos de natureza comportamental ou de condutas.

O primeiro afirma a racionalidade intencional do agente humano, ainda que essa racionalidade seja limitada. As partes que se sentam para definir um acordo contratual não o fazem de maneira desarrazoada.

O segundo pressuposto caracteriza os agentes como propensos a comportamentos oportunistas. Portanto, "não serão confiáveis as promessas de um comportamento responsável que não estejam associadas a um compromisso crível" (Williamson, 1996, p. 136).

Esta frase poderia ser o mote de um analista quando julga o pleito de uma empresa por recursos financeiros de um programa de desenvolvimento regional. $\mathrm{O}$ administrador de incentivos regionais deve estar ciente desse caráter limitado da racionalidade empresarial - e de resto - humana: no afã de receber recursos subsidiados, um empresário pode prometer mais do que pode cumprir.

Mais recentemente, o tema das instituições tem sido incorporado à pesquisa em crescimento endógeno. O estabelecimento de instituições estáveis, ou seja, regras políticas e econômicas, que conduzam a maiores níveis de segurança aos direitos de propriedade, bem como estimulem a produção, a eficiência e a aquisição de habilidades, desestimulando tudo aquilo que desvie o sistema econômico desses aspectos, como, por exemplo, os favorecimentos a grupos de interesse e a corrupção, é um fator-chave para o crescimento, na medida em que cria condições favoráveis para novos investimentos, inclusive em desenvolvimentos tecnológicos. Por esse motivo, os modelos de crescimento endógeno comumente incorporam em suas análises o papel das instituições no crescimento econômico de uma região (Acemoglu et al., 2001).

Excessivamente burocrático e economicista, apesar das referências às variáveis sociais, o texto que recria a Sudene não faz menção a uma necessária mudança institucional. A questão levantada no documento do GTDN sobre essa necessidade não é lembrada no texto frio da Lei.

\footnotetext{
${ }^{23}$ Uma empresa não cresceria, por outro lado, indefinidamente. Isso porque sua estrutura administrativa estaria sujeita a ocorrência de rendimentos decrescentes: "Naturalmente deverá haver um ponto em que os custos da organização de uma transação adicional dentro da empresa sejam iguais aos custos envolvidos na realização da transação no mercado aberto" (Coase, 1996, pp. 37-38).
} 
Existe a possibilidade de que o tema seja tratado nos planos de desenvolvimento regional mencionados como atribuição do novo órgão. As teorias discutidas nesta seção são muito enfáticas sobre a importância do desenho institucional para o desenvolvimento. Por outro lado, a sobre-ênfase nos fundos de investimentos filia a "nova" proposta a um modelo de promoção de desenvolvimento superficial e ultrapassado. Corre-se o risco de desperdiçar os recursos com resultados de curto prazo, atraindo indústria e empreendimentos de curta maturação. Quando a fonte seca, os tais empreendimento vão em busca de novas facilidades.

Já não seria o caso de aplicar tais recursos - cuja origem é inequívoca: tributos pagos pelos trabalhadores do Brasil em sua totalidade - em projetos de desenvolvimento mais perenes? Tema elaborado a seguir.

\section{CONSIDERAÇÕES FINAIS}

Como uma contribuição para a reflexão sobre a nova Sudene, quatro fundamentos são discutidos neste trabalho. Primeiro, todos os países praticam, em maior ou menor grau, algum tipo de política regional e é legítimo que o façam. Independentemente da coloração ideológica predominante em certa época, o fato é que regiões atrasadas demandam algum tipo de intervenção em prol de uma convivência harmônica no plano nacional. Essa premência se torna ainda mais clara quando o termo "regiões" é substituído por "países", como é o caso da União Europeia.

O segundo tópico que o texto procura demonstrar é que o Nordeste é ainda um problema regional e, como tal, nacional. Quando por menos não for, é em nome da manutenção de um pacto federativo que a região deve ser tratada de maneira especial. Por tratamento diferencial entenda-se a execução de políticas públicas além daquelas previstas na dimensão setorial dos ministérios. A correção ou amenização das disparidades seria benéfica não apenas em termos sociais, mas o desenvolvimento de um promissor, sustentável e saudável mercado é algo sempre valorizado numa perspectiva estritamente econômica.

Essa lembrança dos benefícios econômicos de uma eventual redução na desigualdade regional não deve embotar a mente do legislador de políticas públicas a ponto de acreditar que medidas de raiz puramente econômicas, como a concessão de incentivos fiscais, são suficientes para resolver o problema. Este é o terceiro fundamento que este trabalho procura analisar.

A teoria econômica tem ressaltado a importância que o ambiente institucional tem para o desenvolvimento de um país ou de uma região. Crescimento econômico no longo prazo só é mantido ou mesmo ampliado quando o arranjo institucional é favorável. As instituições não são um mero pano de fundo no qual o interesse econômico micromotivado age em prol do benefício comum. Um arranjo institucional desfavorável pode viciar os micromotivos e comprometer toda uma política de concessão de incentivos.

É o caso em que os recursos destinados a um conjunto de empreendimentos industriais elevam o volume de emprego de uma área — reduzindo o de outra mas por pouco tempo. Tão logo novas oportunidades fiscais surjam, haverá novas realocações. Uma política de incentivos promissora é aquela que atrai empreendi- 
mentos e não apenas os realoca (quarto fundamento). Política de crédito fácil tem forte apelo no curto prazo. Isso porque os resultados do uso alternativo mais perene e saudável de recursos públicos, como por exemplo na construção de uma infraestrutura educacional, não são tão visíveis.

Trata-se, contudo, de uma visão de curto prazo. É como se a imagem de uma fábrica em construção despertasse mais anseios que de uma escola de ensino fundamental. Como se a escola também não empregasse. É chegado o momento de repensar, considerando inclusive a experiência internacional, o modelo de políticas regionais no Brasil. A luta por recursos para pôr em prática um mecanismo de incentivos fiscais não deve obscurecer o planejamento mais enraizado na realidade local.

Política de incentivos sem um mapeamento interdisciplinar das instituições e das carências básicas das famílias, política de incentivos pautada apenas na distribuição de recursos públicos é repetir uma paisagem desoladora de ex-empreendimentos incentivados, como abundam na Região Nordeste.

A superação do atraso regional não acontece sem uma grande reforma nas instituições diretamente responsáveis pela manutenção do status quo. Recriar um órgão como a Sudene (Superintendência de Desenvolvimento do Nordeste) com a mera função de administrar fundos para o desenvolvimento, portanto, é incorrer em erro e desperdício de dinheiro público. A Sudene, como abordado no texto, não tem um passado dos mais necessários à região, embora tenha sido responsável direta pela geração de empregos. Se o seu futuro é apenas um retrato do passado, a sua recriação não se justifica.

\section{REFERÊNCIAS BIBLIOGRÁFICAS}

ACEMOGLU, Daron; JOHNSON, Simon; e ROBINSON, James. (2001) "Colonial origins of comparative development: an empirical investigation”, American Economic Review, n. 91, v. 5, p. 1369-1401.

ALMEIDA, Rômulo. (1985) Nordeste: Desenvolvimento Social e Industrialização. Rio de Janeiro: Paz e Terra.

ANDRADE, Manuel C. (1999) A Problemática da Seca. Recife: Liber.

ARTHUR, W. Brian. (1998) Increasing Returns and Path Dependence in the Economy. Michigan: The University of Michigan Press.

BARROS, Roberto M. A. (1997) "Experiência regional de planejamento", in MINDLIN, Betty. (Org.). Planejamento no Brasil, 6. ed. São Paulo: Perspectiva, p. 111-137.

BRESSER-PEREIRA, L. (1998) Economia Brasileira: Uma Introdução Crítica. 3. ed. São Paulo: Editora 34.

CARDOSO, Fernando H. (1997) “Aspectos políticos do planejamento”, in MINDLIN, Betty (Org.). Planejamento no Brasil. 6. ed. São Paulo: Perspectiva, p. 161-184.

CARVALHO, Otomar. (1988) A Economia Política do Nordeste: Secas, Irrigação e Desenvolvimento. Rio de Janeiro: Campus.

COASE, Ronald. (1996) "La naturaleza de la empresa", in WILLIAMSON, Oliver E.; WINTER, Sidney G. (Orgs.). La Naturaleza de la Empresa, Orígenes, Evolución y Desarrollo. Cidade do México. Fondo de Cultura Económica.

COHN, Amélia. (1976) Crise Regional e Planejamento. São Paulo: Perspectiva.

DAVID, Paul. (1985) "Clio and the economics of QWERTY", American Economic Review, v. 75, p. 332-337.

DOWNS, Anthony. (1999) Uma Teoria Econômica da Democracia. São Paulo: Edusp. 
ESPINO, José Ayala. (1999) Instituciones y Economia: Una Introducción ao Neoinstitucionalismo Econômico. Cidade do México: Fondo de Cultura Económica.

FURTADO, Celso. (2007) A Formação Econômica do Brasil. 34 ed. São Paulo: Companhia das Letras. FURTADO, Celso. (1997) A Fantasia Desfeita. Rio de Janeiro: Paz e Terra.

GALVÃO, Olímpio J. A. (1998) "Velhas e novas políticas de desenvolvimento regional à luz dos conceitos de especialização flexível e de novos espaços industriais”, Revista Econômica do Nordeste, v. 29, p. 761-785. Número especial.

GOODMAN, David E.; Albuquerque, Roberto C. (1974) Incentivos à Industrialização e Desenvolvimento do Nordeste. Rio de Janeiro: IPEA/INPES.

GRUPO DE TRABALHO PARA O DESENVOLVIMENTO DO NORDESTE. (1959) Uma Política de Desenvolvimento Econômico para o Nordeste. Rio de Janeiro: Imprensa Nacional.

HIRSCHMAN, Albert O. (1973) Journeys Toward Progress: Studies of Economic Policy-Making in Latin America. Nova York: W.W. Norton \& Company.

JACCOUD, Luciana. (2001) "Experiências internacionais em política regional: o caso da França”.,IPEA: texto para discussão, Brasília, DF, n. 815.

TARGETTI, F.; THIRLWALL, A. P. (1989) The Essential Kaldor. Nova York: Holmes \& Meier:, pp. 311-326.

KRUGMAN, Paul. (1996) The Self-Organizing Economy. Oxford: Blackwell.

LAFER, Celso. (1997) "O planejamento no Brasil: observações sobre o plano de metas (1956-1961)", in MINDLIN, Betty (Org.). Planejamento no Brasil, 6. ed. São Paulo: Perspectiva, p. 29-50.

LANDES, David S. (1998) A Riqueza e a Pobreza das Nações. Rio de Janeiro: Campus.

LEBRET, Louis Joseph (1955) Estudo sobre Desenvolvimento e Implantação de Indústrias Interessando a Pernambuco e ao Nordeste. Recife: CODEPE.

LEWIS, W. Arthur. (1965) The Theory of Economic Growth. New York: Harper.

LILIENTHAL, David E. (1944) Democracy on the March. Nova York: Harper \& Brothers.

MAIA GOMES, Gustavo. (2001) Velhas Secas em Novos Sertões. Brasília, DF: IPEA.

MOSELEY, Malcolm (1999) "Aspectos da política regional européia, com ênfase especial na experiência britânica e nos avanços da 'Abordagem Local'”, in Marcos C. Lima, Rubem Monteiro e Valdeci M. dos Santos (Orgs.), Planejamento Regional em Tempos de Globalização, Recife, UFPE.

MONTEIRO, Rubem; SANTOS, Valdeci M. (Orgs.). (1999) Planejamento Regional em Tempos de Globalização. Recife: UFPE.

NORTH, Douglass C. (1990) Institutions, Institutional Change and Economic Performance. Cambridge: Cambridge University Press.

NORTH, Douglass C. (1994) Custos de Transação, Instituições e Desempenho Econômico. Rio de Janeiro: Instituto Liberal.

OLIVEIRA, Francisco de. (1977) Elegia para uma Re(li)gião. Rio de Janeiro: Paz e Terra.

POLANYI, Karl. (2000) A Grande Transformação. Rio de Janeiro: Campus.

ROBOCK, Stefan H. (1964) Desenvolvimento Econômico Regional. Rio de Janeiro: Fundo de Cultura. SEN, Amartya. (2001) Desigualdade Reexaminada. Rio de Janeiro: Record.

SILVA FILHO, Guerino E. da. (1997) "A interpretação para o atraso relativo do Nordeste a partir da teoria do desenvolvimento econômico periférico da CEPAL”. Revista Econômica do Nordeste, v. 28, n. 4 , p. $433-449$.

TAMER, Alberto. (1968) Nordeste, até quando? São Paulo: APEC.

TSEBELIS, George. (1998) Jogos Ocultos. Tradução de Luiz Paulo Rouanet. São Paulo: Edusp.

VILLA, Marco Antônio. (2000) A Vida e Morte no Sertão: Histórias da Secas no Nordeste nos Séculos XIX e XX. São Paulo: Ática.

WEBER, Max. (1991) Economia e Sociedade. Brasília, DF: Ed. da UnB.

WILLIAMSON, J. G. (1968) "Regional inequality and the process of national evelopmente: a description of the patterns", in NEEDLEMAN, L. (Ed.). Regional Analysis. Suffolk: Penguin Books, p. 99-158.

WILLIAMSON, Oliver E. (1996) "La lógica de la organización económica", in WILLIAMSON, Oliver E.; WINTER, Sidney G. (Orgs.), La naturaleza de la empresa, Orígenes, evolución y desarrollo. Cidade do México: Fondo de Cultura Económica.

WRIGHT, Gavin. (1986) Old South, New South: Revolutions in the Southern Economy since the Civil War. New York: Basic Books. 